Elsevier

NSM 00887

\title{
A new approach for the evaluation of recovery after peripheral nerve damage
}

\author{
R. Gerritsen van der Hoop, J.H. Brakkee, A. Kapelle, M. Samson, \\ P. de Koning and W.H. Gispen \\ Division of Molecular Neurobiology, Rudolf Magnus Institute for Pharmacology and Institute of Molecular Biology \\ and Medical Biotechnology, University of Utrecht, Utrecht (The Netherlands) \\ (Received 22 February 1988) \\ (Revised 9 May 1988) \\ (Accepted 13 July 1988)
}

Key words: Regeneration; Tail crush; ORG.2766; Functional recovery

\begin{abstract}
The major caudal nerves of the rat provide an excellent model for longitudinal evaluation of nerve repair following a crush lesion. The surgical procedure and the method for testing sensory recovery are described in detail. Using this technique a clear, positive effect of ORG.2766 (an ACTH (4-9) analog) on the regeneration of sensory nerves could be shown. Results support the suggestion that ORG.2766 enhances the initial sprouting response, rather than exerting an effect on the growth rate of newly developed sprouts.
\end{abstract}

\section{Introduction}

Following damage of peripheral nerves both velocity of recovery and the amount of function regained are important parameters to investigate. There are, however, only few techniques available that allow monitoring of both these qualities longitudinally (D'Amour, 1941; Guttman, 1942; Legrain, 1977). Recently a useful method in this respect was described by De Koning et al. (1986). Regeneration of the sciatic and tibial nerve after crush damage was measured by testing recovery of sensory function on the footsole of the rat at 4 different points. Though this technique is reliable and reproducible, a drawback is the small distance between the consecutive measuring points on the

\footnotetext{
Correspondence: W.H. Gispen, Division of Molecular Neurobiology, Rudolf Magnus Institute for Pharmacology and Institute of Molecular Biology and Medical Biotechnology, University of Utrecht, Padualaan $8,3584 \mathrm{CH}$ Utrecht, The Netherlands.
}

sole used for calculating the speed of regeneration. In the present study the possible use of the caudal nerve of the rat for measuring recovery of sensory nerve fibers after crush damage was evaluated.

Derivatives of ACTH and $\alpha$-MSH have been shown to exert beneficial effects on regenerating peripheral nerve (Strand, 1980; Bijlsma, 1981: Saint-Come, 1982). In earlier studies using the sciatic crush method a positive effect of ORG.2766 on the recovery of sensory function following a crush lesion was found (Bijlsma, 1983; De Koning, 1986; Verhaagen, 1986).

In order to assess the usefulness of the caudal nerve crush model the effect of ORG.2766, a known neurotrophic agent, was studied.

\section{Material and Methods}

Animals

Male Wistar rats of an inbred strain (CPB, TNO, Zeist, NL) weighing between 140 and $170 \mathrm{~g}$ were used (length of the tail approx. $14 \mathrm{~cm}$ ). The 
animals were housed in macrolon cages (RUCO. NL), 4 per cage, on sawdust with free access to commercial rat chow and water. A dark-light cycle of $12 \mathrm{~h}$ was maintained, lights being on from 7.30 to $19.30 \mathrm{~h}$.

\section{Anesthesia}

Rats were anesthetized by means of a s.c. injection with Hypnorm (Duphar, Weesp, NL), containing fluanisone $(10 \mathrm{mg} / \mathrm{ml})$ and phentanylcitrate $(0.2 \mathrm{mg} / \mathrm{ml})$; dose $0.8 \mathrm{ml} / \mathrm{kg}$ b.wt.

\section{Anatomy}

The tail of the rat is innervated by 4 caudal nerves. The minor caudal nerves are situated in the dorsal part and the major caudal nerves in the ventral part of the tail. The innervation zones overlap considerably. Thus, transection of both minor nerves does not result in a detectable loss of sensibility in the tail. In order to study regeneration of the major caudal nerves the minor ones were transected and the major ones were crushed.

\section{Surgery}

Parallel to the lateral caudal vein, a $2 \mathrm{~cm}$ long incision was made, $1.5 \mathrm{~cm}$ distal to the base of the tail. The skin was separated from underlying tissue by blunt preparation techniques. Subsequently, an incision was made in the lower part of the dorsal tendon sheet unto the vertebrae (see Fig. 1). The minor caudal nerve was raised and a part of at least $0.5 \mathrm{~cm}$ was removed. An incision was made in the middle of the ventral tendon sheet, exposing the major caudal nerve. The nerve was raised and crushed for $30 \mathrm{~s}$, as described by De Koning et al. (1986). A Kocher crush forceps with a waffle shaped inner side of the mouth was used. The crush had a standardized width of 2 $\mathrm{mm}$. An ink line was drawn on the skin to indicate the precise crush position. The procedure was then repeated on the other side of the tail. The wound was closed by gluing the wound sides, using a cyano acrylate ester (Deltafix). Fine ink markings were placed in distal direction at $1 \mathrm{~cm}$ intervals from the first marking. These markings remained visible throughout the experimental period.

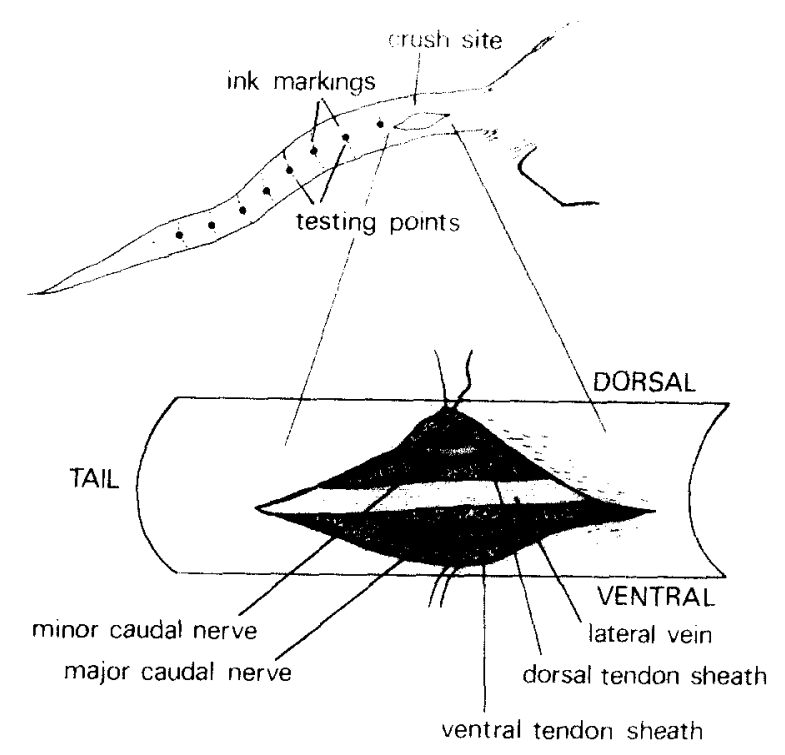

Fig. 1. Schematic representation of the surgical approach to the caudal nerves of the rat. Also shown are the different testing points.

\section{Peptide treatment}

ORG.2766, a degradation resistant, ACTH (4-9) analog (H-Met(O2)-Glu-His-Phe-D-LysPhe-OH, Organon, Oss, NL) was dissolved in $0.1 \% \mathrm{BSA} / 0.05 \mathrm{M} \mathrm{HCl}$, and diluted with $0.9 \%$ $\mathrm{NaCl}$ to a final concentration of $2 \mu \mathrm{g} / \mathrm{ml}(0.5$ $\mathrm{ml} / \mathrm{rat})$. Medication was administered by a s.c. injection in the neck. Control animals were given $0.1 \% \mathrm{BSA} / 0.05 \mathrm{M} \mathrm{HCl}$, diluted with $0.9 \% \mathrm{NaCl}$ up to a final volume of $0.5 \mathrm{ml} / \mathrm{rat}$.

\section{Testing procedure}

A $540 \mathrm{~V}$ (AC) shock source was used with a standard series resistance of $390 \mathrm{M} \Omega$ and a stepwise variable series resistance of $0-5 \mathrm{M} \Omega$. The variable resistance could be adjusted to give a $0.1-1.0 \mathrm{~mA}$ current when the skin closes the circuit between the cathode and anode. A pinpoint electrode with a diameter of $1 \mathrm{~mm}$ was used as anode. Functioning as cathode, a spring clip, wetted with saline in order to facilitate conduction, had been placed distal to the anode position. The distance between cathode and anode was kept at $5 \mathrm{~cm}$ at all times. In testing different cathode-anode intervals, a distance of $5 \mathrm{~cm}$ proved to be most effective. Shorter intervals or the use of bipolar electrodes led to less equivocal results, 
perhaps due to the variable resistance in the (thick) skin of the tail.

Touching the tails of control rats, thus presenting for an instant a noxious stimulus of $0.5 \mathrm{~mA}$, invariably and instantaneously resulted in vocalization. This response was used as a functional index of sensory recovery of the caudal nerves. Rats were tested daily between 10.00 and $11.00 \mathrm{~h}$. Return of sensory function at each of the ink markings was assessed starting from the most distal part of the tail. At first a current of $0.5 \mathrm{~mA}$ was applied. In case no vocalization was noted, a stimulus of $0.7 \mathrm{~mA}$ was presented to the same spot on the tail. No injury to skin or s.c. tissue was observed using these current strengths. Animals were only restrained from moving by holding them lightly. No signs of resistance to the testing procedure were noted. At random intervals, rats were tested with zero current strength to detect possible false positive reactions or conditioning effects resulting from repeated exposure to the noxious stimulus.

\section{Experiments}

In the first experiment 48 rats were randomly divided into 4 groups of 12 animals. One group remained untreated. The second group underwent a sham surgical procedure, in which the major and minor caudal nerves were approached and raised only. In animals of the third group the minor caudal nerves were cut, but no crush lesion was placed in the major caudal nerves. These 3 groups served as controls. Animals of the fourth group were subjected to the complete surgical procedure. All rats were tested with at least two test shocks per trial per day.

In the second experiment 24 rats were randomly divided into two groups of 12 rats. Their minor caudal nerves were both cut and a crush lesion was placed in both major caudal nerves. One group received ORG. 2766 every $48 \mathrm{~h}$ and the other group received saline injections. The functional testing procedure and drug administration were independently performed by two separate investigators and continued until all animals responded to the $0.5 \mathrm{~mA}$ stimulus at a distance of 4 $\mathrm{cm}$ from the site of the crush lesion. The treatment code was broken after data analysis. The statis- tical significance of group differences was assessed by means of an analysis of variance with repeated measures followed by a supplemental t-test. A regression analysis was used to calculate linear relations.

\section{Results}

Efficacy of the crush lesion

The use of sutures for closing surgical wounds was abandoned since this procedure caused obstructive edema, possibly hampering regeneration. In a pilot study it was found that adequate wound repair (normal healing period, absence of reactions caused by infection or allergy) took place when glue was used as a wound adhesive. Slight. transient swelling of the tail at the site of the wound was seen directly following surgery. All rats belonging to the first 3 groups in the first experiment responded to test shocks of both 0.5 and $0.7 \mathrm{~mA}$ from day 1 onwards. Rats did not vocalize to anode contact without a current running. In group 4 no rats vocalized on testing with either 0.5 or $0.7 \mathrm{~mA}$ at day 1 , indicating that a total loss of sensory function in the tail had ensued as a result of the crush procedure. Fig. 2 illustrates the mean time period of return of reaction to the stimulus at different distances from the place of the crush lesion.

At $2 \mathrm{~cm}$ the mean stimulus detection time was 9.1 days at $0.5 \mathrm{~mA}$ and 7.3 days at $0.7 \mathrm{~mA}$ stimulus strength. As time progressed, reactions to stimuli were detected at adjacent ink markings. On all measuring points the reaction to a stimulus of $0.7 \mathrm{~mA}$ appeared earlier than reaction to a stimulus of $0.5 \mathrm{~mA}$. A linear relationship between distance from the crush site and day of detection of the stimulus was found for both current strengths (correlation coefficients 0.973 and 0.974 . respectively, both $P<0.0001$ ). Reinnervation following the crush lesion took place at an estimated speed of $1.6 \mathrm{~mm} /$ day at both stimulus strengths.

\section{Effect of $O R G .2766$ on regeneration}

Two animals were excluded from this experiment, one in each group, because of injury to the tail as a result of automutilation or biting by their 


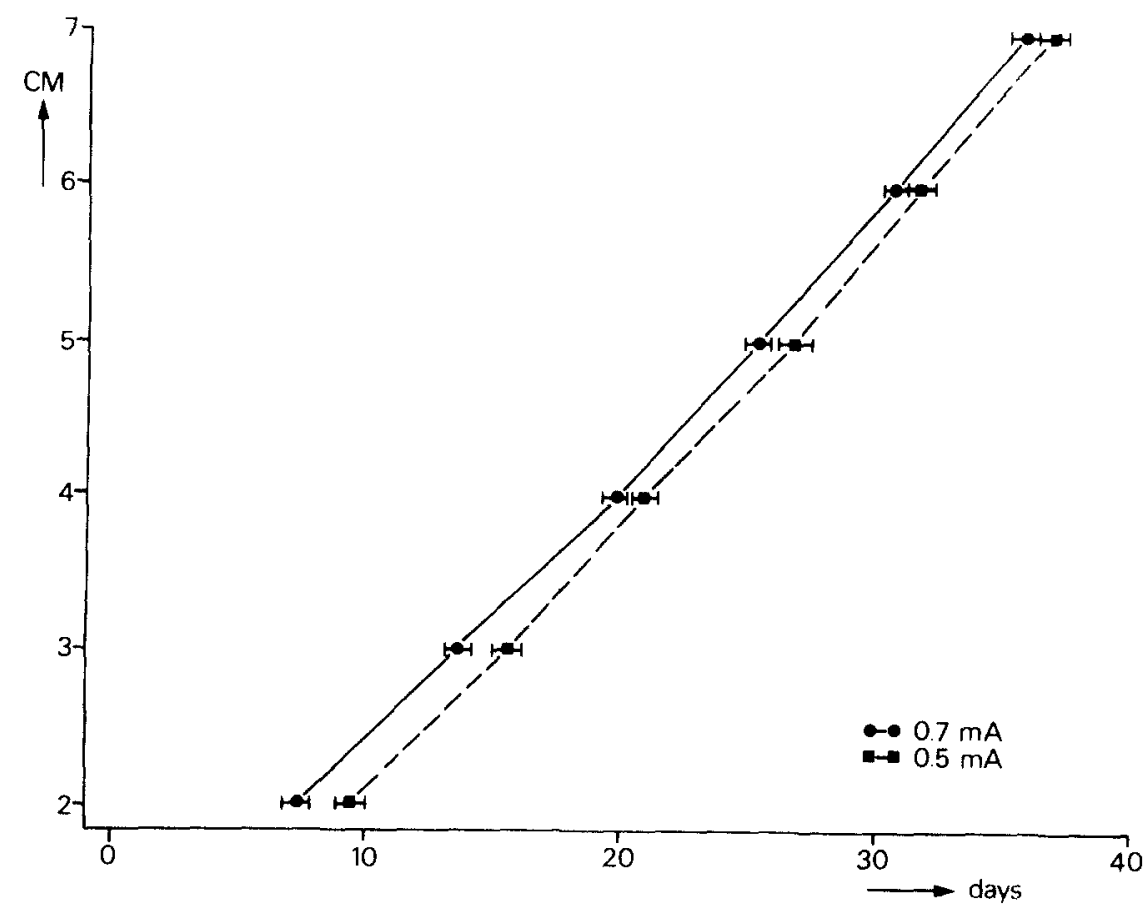

Fig. 2. Average day of recovery (positive vocalization response) at various distances from crush site using stimulus strengths of 0.5 and $0.7 \mathrm{~mA}$. Correlation coefficients 0.974 and $0.973(P<0.0001)$. Calculated linear relations of $y=0.16 \mathrm{X}+0.79$ and $y=0.16 \mathrm{X}+$ 0.50 , respectively.
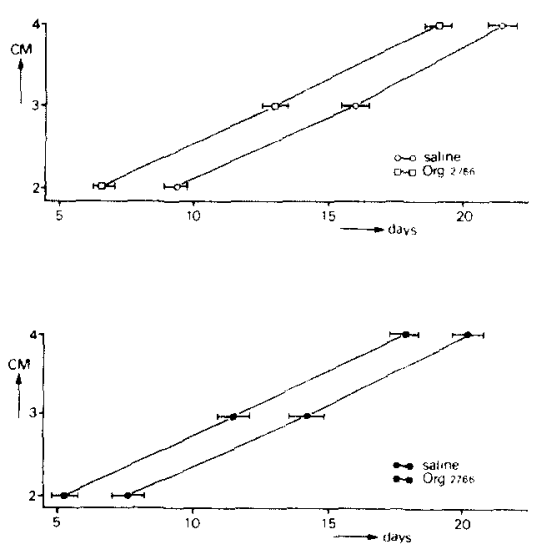

Fig. 3. Average day of recovery (positive vocalization response) at various distances from the crush site in two groups (ORG.2766 versus saline) using a stimulus strength of $0.5 \mathrm{~mA}$ (A) and $0.7 \mathrm{~mA}$ (B). Correlation coefficients $0.92,0.93$ and $0.93,0.92$, respectively $(P<0.0001)$. Calculated linear relations of $y=0.14 \mathrm{X}+1.23, y=0.14 \mathrm{X}+0.79$ and $y=0.14 \mathrm{X}+1.32$, $y=0.13 \mathrm{X}+1.14$, respectively. Differences between ORG.2766and saline-treated animals: $P<0.001$ (both current strengths). cage partners. In Fig. 3 the effect of s.c. treatment with ORG.2766 on the regeneration following a crush lesion of the caudal nerve is shown. Fig. 3 illustrates that the return of stimulus detection in the tails of saline treated rats proceeded along a line with almost identical values as compared to the previous experiment (correlation coefficients 0.919 and 0.929 , both $P<0.0001$, slopes 0.13 and $0.14)$.

However, at both stimulus strengths the time needed to detect the testing stimulus was significantly shorter in the peptide-treated group, in that the vocalization response occurred approximately 2.3-2.5 days earlier at each testing point (correlation coefficients 0.921 and 0.931 , both $P<0.0001$, slopes both 0.14 ). The rate of regeneration was in the same order as that seen in the saline-treated control group ( $1.4 \mathrm{~mm} /$ day both groups). 


\section{Discussion}

Previously it has been shown by various authors that the crush lesion is highly reproducible with regard to the degree of damage. All fibers degenerate following the crush lesion and a nearly equal number of fibers regenerate (Legrain, 1977; Mira, 1977; De Koning, 1986). A test procedure employing local application of small electric currents was used to monitor recovery of sensory function following a crush lesion of the caudal nerves of the rat. In general, reaction to painful stimuli is known to be part of the initial signs of recovery following damage of peripheral nervous tissue (Omer, 1981). The results of the first experiment demonstrate that the process of caudal nerve regeneration can be recorded longitudinally. An obvious additional advantage of such a longitudinal test procedure is that fewer animals are needed to study the time course of peripheral nerve regeneration. Testing with stimuli of 0.5 and $0.7 \mathrm{~mA}$ resulted in parallel lines indicating that a similar process was investigated with both current strengths. The overlapping curves of the untreated animals in both experiments indicate that the crush lesion of the caudal nerve can be performed in a highly reproducible manner. This is also apparent from the small standard errors at each of the testing points in all groups tested.

Furthermore, the method allows measuring and registering the process of regeneration from day 4 onwards, which certainly is an advantage as compared to other studies on peripheral regeneration (Bijlsma, 1983; De Koning, 1986). Also, most importantly, the repair process can be observed throughout a long period of time (if desired up to approximately 35 days). In none of the rats studied, a test procedure conditioning occurred.

In both experiments a relatively low rate of nerve regeneration was found (1.6 and $1.4 \mathrm{~mm} /$ day). Earlier publications showed the speed of reinnervation to be near to that of the slow component of axonal transport $(2.9 \mathrm{~mm} /$ day; De Koning, 1986). Those experiments were not performed in the tail but in parts of the animal body with a higher temperature. The mean temperature of the tail is about $25^{\circ} \mathrm{C}$, which is almost $10^{\circ} \mathrm{C}$ lower than for instance that of the footsole. It is well-known that a decrease in temperature affects the conduction velocity through nerve fibers with about $1.3 \mathrm{~m} / \mathrm{s} /{ }^{\circ} \mathrm{C}$ (Myoshi, 1973). Possibly in the relatively cold tail, reinnervation occurs at a lower speed as a result of relatively slow, temperature-dependent axonal repair processes in the caudal nerve.

The results of the second experiment are in line with the previous reports by Bijlsma (1983), De Koning (1986) and Verhaagen (1986) regarding the neurotrophic actions of ORG.2766. Gispen et al. (1970) showed that the reaction itself to noxious electrical stimuli is not influenced by the use of ACTH-like peptides, while no systemic effects have ever been observed (De Wied, 1982). Though in this experiment only regeneration of sensory pain fibers was studied. the data suggest that the neurotrophic effect of ORG.2766 is not specific for a given peripheral nerve, but presumably can be observed in any peripheral nerve following damage. In the present study a fixed 2-day advantage in recovery of the ORG.2766-treated group over the control group persisted during the whole of the experiment, indicating that ORG.2766 is capable of facilitating the formation of sprouts following damage, rather than enhancing the rate of outgrowth of the sprouts ensuing this initial phase, as was already suggested in earlier studies (De Koning, 1986; Verhaagen, 1986). Recently, Saint-Come and Strand (1987) concluded likewise when studying the effects of ORG.2766 on motor nerve regeneration.

In conclusion, the present study showed that the caudal nerve crush in rats, monitoring the return of reaction to noxious stimuli in a longitudinal design, is a valuable, reproducible and accurate experimental procedure in the study of regeneration of peripheral nervous tissue and its facilitation by neurotrophic pharmacotherapy.

\section{References}

Bijlsma, W.A., Jennekens, F.G.I. Schotman, P. and Gispen, W.H. (1981) Effects of corticotropin (ACTH) on recovery of sensorimotor function in rats - a structure-activity study, Eur. J. Pharmacol., 76: 73-79.

Bijlsma, W.A., Jennekens, F.G.I., Schotman, P., Gispen, W.H. and De Wied, D. (1983) Enhanced recovery of sensorimo- 
tor function in rats related to melanotrophic activity of ACTH/MSH, Eur. J. Pharmacol., 92: 132-136.

D'Amour, F.E. and Smith, L. (1941) A method for determining loss of pain sensation, J. Pharmacol. Exp. Ther., 72: 74-79.

De Koning, P., Brakkee, J.H. and Gispen, W.H. (1986) Methods for producing a reproducible crush in the sciatic and tibial nerve of the rat and rapid precise testing of return of sensory function. Beneficial effects of melanocortins, $J$. Neurol. Sci., 74: 237-246.

Devor, M., Schonfeld, D., Seltzer, Z. and Wall. P.D. (1979) Two modes of cutaneous innervation following peripheral nerve injury, J. Comp. Neurol., 185: 211-220.

De Wied, D. and Jolles, J. (1982) Neuropeptides derived from proopiocortin: behavioral, physiological and neurochemical effects, Physiol. Rev., 62: 976-1059.

Gispen, W.H., Van Wimersma Greidanus, Tj.B. and De Wied, D. (1970) Effects of hypophysectomy and ACTH (1-10) on responsiveness to electric shock in rats, Physiol. Behav., 5: $143-146$.

Guttman, E., Guttman, L., Medawar, P.B. and Young, J.Z. (1942) The rate of regeneration of nerve, J. Exp. Biol., 19: 14-44.

Legrain, Y. (1977) Méthode de comparison de la vitesse de regeneration des fibres du nerf sciatique du rat, J. Physiol. (Paris), 73: 13-22.
Mira, J.C. (1977) Étude quantitative sur la regeneration des fibres regenerées après une congelation localisée, Arch Anat. Microsc. Morphol. Exp., 66: 1-16.

Myoshi, T. and Goto, I. (1973) Serial in vivo determinations of nerve conduction velocity in rat tails: physiological and pathological changes, Electroencephalogr. Clin. Neurophysjol., 35: 125-131

Omer, G.E. (1981) Methods of assessment of injury and recovery of peripheral nerves, Surg. N. Clin. Am., 61: 303-319.

Saint-Come, C., Acker, G.R. and Strand. F.L. (1982) Influences on the development and regeneration of motor performance, Peptides, 3: 439-449.

Saint-Come, C.M. and Strand, F.L. (1987) ACTH (4-9) analog (ORG.2766) improves qualitative and quantitative aspects of motor nerve regeneration, Peptides, in press

Strand, F.L. and Kung, T.T. (1980) ACTH accelerates recovery of neuromuscular function following crushing of peripheral nerve, Peptides, 1: 135-138.

Verhaagen, J., Edwards, P.M., Jennekens, F.G.I., Schotman, P. and Gispen, W.H. (1986) $\alpha$-Melanocyte-stimulating hormone ( $\alpha-\mathrm{MSH})$ stimulates the outgrowth of myelinated fibers after peripheral nerve crush, Exp. Neurol., 92 $451-454$ 